\title{
The cadaveric anatomy of the distal radius: implications for the use of volar plates
}

\author{
PA McCann, D Clarke, R Amirfeyz, R Bhatia
}

University Hospitals Bristol NHS Foundation Trust, UK

ABSTRACT

INTRODUCTION Fractures of the distal radius are common upper limb injuries, representing a substantial proportion of the trauma workload in orthopaedic units. With ever increasing advancements in implant technology, operative intervention is becoming more frequent. As growing numbers of surgeons are performing operative fixation of distal radial fractures, an accurate understanding of the relevant surgical anatomy is paramount. The flexor carpi radialis (FCR) tendon forms the cornerstone of the Henry approach to the volar cortex of the distal radius. A number of key neurovascular structures around the wrist are potentially at risk during this approach, especially when the FCR is mobilised and placed under retractors.

METHODS In order to clarify the safe margins of the FCR approach, ten fresh frozen human cadaver limbs were dissected. The location of the radial artery, the median nerve, the palmar cutaneous branch of the median nerve and the superficial branch nerve were measured with respect to the FCR tendon. Measurements were taken on a centre-to-centre basis in the coronal plane at the watershed level. In addition, the distances between the tendons of brachioradialis, abductor pollicis longus and flexor pollicis longus, and the radial artery and median nerve were measured to create a complete picture of the anatomy of the FCR approach to the distal radius.

RESULTS The structure most at risk was the palmar cutaneous branch of the median nerve. It was located on average $3.4 \mathrm{~mm}$ from the FCR tendon. The radial artery and the main trunk of the median nerve were located $7.8 \mathrm{~mm}$ and $8.9 \mathrm{~mm}$ from the tendon. The superficial branch of the radial nerve was $24.4 \mathrm{~mm}$ from the FCR tendon and $11.1 \mathrm{~mm}$ from the brachioradialis tendon.

CONCLUSIONS Operative intervention is not without complication. We believe a more accurate understanding of the surgical anatomy is key to the prevention of neurovascular damage arising from the surgical management of distal radial fractures.

\section{KEYWORDS}

Distal radius fracture - ORIF - Cadaveric - Surgical anatomy

Accepted 30 October 2011

\section{CORRESPONDENCE TO}

Philip McCann, 80 Raleigh Road, Southville, Bristol BS3 1QT, UK

T: +44 (0)753 308 8383; E: pasmccann@hotmail.com

The operative treatment of distal radial fractures with volar locking plates has grown exponentially in recent years. ${ }^{1}$ It is thought that such implants confer a range of benefits in the treatment of this common injury. They permit surgeons to reconstruct complex periarticular fractures accurately and their innate biomechanical strength allows for immediate rehabilitation..$^{2,3}$ In addition, the pronator fossa is thought to provide an ideal position for implant positioning as the hardware is covered by the volar structures of the distal forearm.

Multiple studies in the literature have highlighted the advantages of volar locking plates in reconstruction of both intra-articular and extra-articular injuries. ${ }^{4-6}$ They have been shown to be superior to the traditional treatment modalities such as percutaneous pinning ${ }^{7-9}$ and external fixation. ${ }^{10}$

The surgical approach to the volar cortex of the distal radius is guided by the flexor carpi radialis (FCR) tendon. This structure forms the basis of both the traditional Henry approach, in the interval between the tendon and the radial artery, ${ }^{11}$ and the Orbay modification, which augments the traditional approach by including a release of the osseous insertion of the brachioradialis tendon to facilitate fracture reduction. ${ }^{12}$

An accurate understanding of the tendons' neurovascular relations is therefore fundamental in avoiding iatrogenic damage during the initial stages of the approach to the fracture plane. The FCR is bordered on its ulnar aspect by both the main trunk of the median nerve and the smaller palmar cutaneous branch of the median nerve. Its radial relations consist of the radial artery, prior to its division into palmar and scaphoid branches, the brachioradialis tendon and the superficial branch of the radial nerve. Any of these structures may theoretically be injured during the approach to the volar cortex of the radius.

The aim of this study was to accurately map the key neurovascular and tendonous structures of the volar aspect of the forearm as they relate to the FCR tendon. With this 


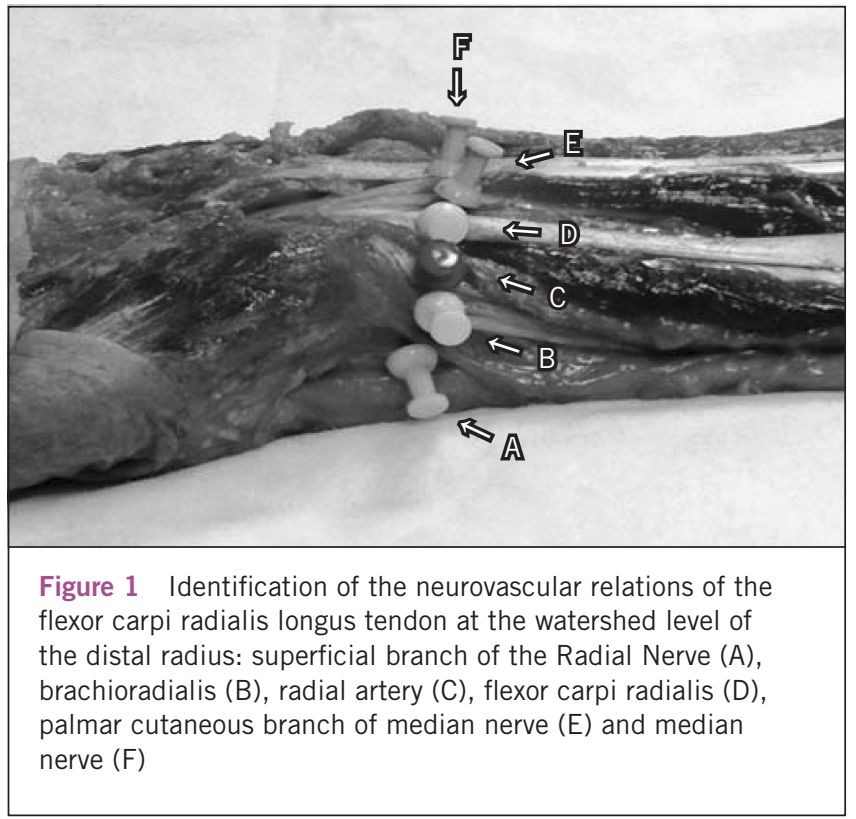

knowledge the surgeon should be able to more accurately appreciate the three-dimensional anatomy encountered during the approach to the fracture plane and thus avoid iatrogenic injury.

\section{Methods}

Local ethical approval to perform cadaveric dissection was obtained. Five pairs of fresh frozen forearms were procured. A modification of the standard FCR technique was used for dissection in each of the specimens. This was designed to enable full visualisation of the volar structures of the distal forearm. After the initial longitudinal skin incision was made, beginning from the scaphoid tubercle at the level of the distal palmar skin crease and extending proximally along the midpoint of the FCR tendon, full thickness skin flaps were elevated on both the radial and ulnar aspects of the tendon and retracted to enable complete visualisation of the volar aspect of the forearm (Fig 1).

The FCR tendon was secured with a $21 \mathrm{G}$ needle and fixed in situ. The radial artery, the brachioradialis tendon and the superficial branch of the radial nerve were identified on the radial aspect of the tendon. The terminal sensory branch of the radial nerve was identified proximally where it emerged under the brachioradialis tendon and then secured with a needle at the watershed level of the distal radius. The brachioradialis tendon was located distally at its osseous insertion on the radial styloid. The abductor pollicis longus was identified radial to this. The flexor pollicis longus tendon was located immediately radial and deep to the FCR tendon.

Ulnar to the FCR tendon, the palmar cutaneous branch of the median nerve was located by identifying its proximal origin on the ulnar aspect of the main trunk of the median nerve and following its course distally close to the FCR tendon sheath. The main trunk of the median nerve was dif- ferentiated from the surrounding flexor tendons by the enveloping vasa vasorum.

All measurements were taken on a centre-to-centre basis at the watershed level of the distal radius. This is an anatomical constant, formed by the distal physeal scar, and serves as a landmark during surgical dissection in fracture surgery. It also corresponds to the optimal site of implant positioning, immediately proximal to the volar lip of the distal radius. ${ }^{13}$ This point was chosen as it was felt it would be reproducible in vitro.

\section{Results}

On the ulnar aspect of the FCR tendon, the palmar cutaneous branch of the median nerve and the main trunk of the median nerve were located at $3.4 \mathrm{~mm}$ and $8.9 \mathrm{~mm}$ respectively. On the radial aspect of the FCR tendon, the radial artery, the brachioradialis tendon and the superficial branch of the radial nerve were located at $7.8 \mathrm{~mm}, 13.3 \mathrm{~mm}$ and $24.4 \mathrm{~mm}$ respectively. The brachioradialis tendon was located, on average, $5.5 \mathrm{~mm}$ from the radial artery and $11.1 \mathrm{~mm}$ from the superficial branch of the radial nerve. The complete range of measurements regarding the relationships to the FCR tendon is displayed in Table 1.

The critical finding was that the palmar cutaneous branch of the median nerve was located at $3.4 \mathrm{~mm}$ (SD: $2.7 \mathrm{~mm}$ ) on the ulnar aspect of the FCR tendon. The intervals from the midpoint of the FCR tendon to the main trunk of the median nerve and the radial artery were $8.9 \mathrm{~mm}$ (SD: $2.6 \mathrm{~mm}$ ) and $7.8 \mathrm{~mm}$ (SD: $2.0 \mathrm{~mm}$ ) respectively. The relations of the radial artery and the superficial branch of the radial nerve to the brachioradialis tendon are also important when considering a tenotomy to facilitate fracture reduction.

\begin{tabular}{|llll|}
\hline Table 1 & Volar structure intervals & & \\
\hline & Mean (mm) & $\begin{array}{l}\text { Standard } \\
\text { deviation } \\
(\mathbf{m m})\end{array}$ & $\begin{array}{l}\text { Range } \\
(\mathbf{m m})\end{array}$ \\
\hline FCR - MN & 8.9 & 2.56 & $5-12$ \\
\hline FCR - RA & 7.8 & 1.99 & $5-10$ \\
\hline FCR - PCBMN & 3.4 & 2.72 & $1-9$ \\
\hline FCR - BR & 13.3 & 4.44 & $6-20$ \\
\hline FCR - SBRN & 24.4 & 8.86 & $18-41$ \\
\hline MN - RA & 18.7 & 6.14 & $11-30$ \\
\hline MN - BR & 20.5 & 2.64 & $18-27$ \\
RA - FPL & 11.6 & 3.06 & $8-18$ \\
\hline RA - BR & 5.3 & 1.95 & $2-7$ \\
BR - APL & 5.9 & 1.59 & $3-9$ \\
\hline
\end{tabular}

$\mathrm{FCR}$ = flexor carpi radialis; $\mathrm{MN}=$ median nerve; $\mathrm{RA}=$ radial artery; PCBMN = palmar cutaneous branch of the median nerve; $\mathrm{BR}=$ brachioradialis; SBRN = superficial branch of the radial nerve; FPL $=$ flexor pollicis longus; $\mathrm{APL}=$ abductor pollicis longus 


\section{Discussion}

It has been noted in the literature that the use of volar locked plates is growing exponentially, both in North America ${ }^{1}$ and in Europe. ${ }^{14}$ Examining the surgical logbooks of senior orthopaedic trainees in 2008 Koval et al found that open reduction and internal fixation was the preferred treatment option in $81 \%$ of distal radial fractures, a remarkable increase from $42 \%$ over a period of just eight years. ${ }^{1}$ Concerns have also been voiced by Downing and Karantana over the rapid expansion in the use of volar plating systems and the role of industry in driving the enthusiasm for this new technology. ${ }^{14}$

While few would argue that volar locking plates allow accurate periarticular reconstruction and in the majority of cases leads to satisfactory functional outcomes, one must also acknowledge the significant complication rates, which approach $30 \%$ in some series. ${ }^{6,15,16}$ Problems usually relate to either malpositioning of the hardware or damage to neurovascular structures surrounding the fracture. ${ }^{17,18}$ It follows that by determining the margins around the FCR tendon, the surgeon may reduce the risk of iatrogenic damage.

There are numerous examples in the literature citing harm to the soft tissue structures around the distal radius. These fall broadly into four groups: the flexor tendons, the extensor tendons (which may represent either tenosynovitis or frank rupture in either group), the vascular structures and the terminal branches of the peripheral nerves.

Regarding flexor tendon damage, the majority of reports seem to concern acute damage to the flexor pollicis longus tendon. ${ }^{19-21}$ The flexor digitorum profundus tendon may also be involved. ${ }^{22}$ Flexor tendon ruptures may also occur long after the acute injury as a result of attrition due to fracture malunion $^{25}$ or against prominent implants. ${ }^{24-26}$ Accurate positioning of the plate in the pronator fossa is thought to reduce such risk. It has been shown that implant positioning distal to the watershed line of the distal radius (the reference level for soft tissue measurement in this study) increases the risk of tendon attrition. ${ }^{27}$ Formal preservation of the pronator quadratus has been suggested as a technique to avoid this complication. ${ }^{28}$ Tendon incarceration in the actual fracture fragments ${ }^{29}$ and the volar plate screw holes ${ }^{30}$ has also been noted.

Extensor tendon injury is reported less frequently, affecting both the extensor pollicis longus and extensor digitorum tendons. These have been noted to occur in the acute as well as the chronic phase. In the former, injury may be due to direct tendon laceration at the time of surgery while drilling the distal screw holes ${ }^{31}$ and in the latter, by attrition on prominent screw tips. ${ }^{32}$ Awareness of this issue has been raised in the literature, with cadaveric assessment of drill tip placement identifying 'at risk' screw holes. ${ }^{35}$ However, this is difficult to predict as the drill angle will be altered by the precise plate position on the palmar surface of the radius. ${ }^{34}$

Damage to the radial artery has been noted in a number of cases. This is usually manifested as a direct tear of the vessel at the time of surgery ${ }^{35,56}$ but latent pseudoaneursym, ${ }^{37}$ arteriovenous fistula formation ${ }^{38}$ and lymphoedema ${ }^{39}$ have also been cited.

With respect to the neural structures around the wrist, median nerve neuropathy is perhaps the most concerning. ${ }^{16}$
Nevertheless, it may be difficult to distinguish between a carpal tunnel syndrome caused by the initial traumatic insult and a carpal tunnel syndrome that is the result of incongruous soft tissue handling and overzealous retraction at operation. The incidence of median nerve dysfunction after volar plating is believed to be $2-14 \% .{ }^{17}$ Damage to the smaller nerve branches (eg the palmar cutaneous branch of the median nerve and the superficial branch of the radial nerve) is also difficult to quantify but is important as disruption of these terminal sensory branches is implicated in the development of complex regional pain syndrome, which has an estimated incidence of 3-10\%. ${ }^{17}$

The palmar cutaneous branch of the median nerve, which supplies sensory innervation to the thenar eminence, arises approximately $4.4 \mathrm{~cm}$ proximal to the wrist crease and travels in a radial direction prior to descending between the superficial and deep layers of the flexor retinaculum and into the palm, where it arborises into a number of minute branches. ${ }^{40,41}$ Trauma to this cutaneous sensory nerve has been implicated in the development of chronic wrist pain, 'pillar pain', increased scar tenderness and complex regional pain syndrome. ${ }^{42,43}$ Damage to this branch by aggressive soft tissue handling may therefore render it liable to injury. As the nerve passes obliquely across the distal aspect of the volar forearm, it is also liable to injury if there is any inaccuracy in the skin incision over the FCR tendon. While relatively easy to palpate in the majority of cases, pronounced soft tissue swelling in high energy injuries may render the structure difficult to locate.

The superficial branch of the radial nerve lies on the radiodorsal aspect of the forearm, superficial to the second and third extensor compartments. Direct injury to this structure has been reported infrequently with respect to volar plating $^{44}$ but it is widely accepted to be at risk during K-wire stabilisation. ${ }^{45}$ Cadaveric studies have highlighted that this branch, in addition to the tendons of the first and second extensor compartments, is at risk of direct perforation during the passage of percutaneous pins. ${ }^{46-48}$ Volar locked plating may also pose a risk as most systems employ a screw hole directed at the radial styloid to support the radial column. Hence, it may be at risk from drill tip perforation. The vulnerability of this structure has led some authors to suggest direct intra-operative mobilisation of this branch. ${ }^{49}$

The location of this structure is also important if a release of the brachioradialis tendon is being considered as this terminal nerve branch is $11.1 \mathrm{~mm}$ from the tendon. We therefore recommend that this release is performed under direct vision to avoid damage to the superficial branch of the radial nerve on the radial aspect of the brachioradialis tendon and the radial artery on the ulnar aspect.

We have previously reported on the relations of the FCR tendon in vivo as imaged with magnetic resonance imaging (MRI). ${ }^{50}$ While this enabled us to achieve a picture of the safe margins around the tendon as bordered by the median nerve and the radial artery, due the sensitivity of MRI, visualisation of the smaller structures such as the palmar cutaneous branch of the median nerve and the superficial branch of the radial nerve was not possible. As a result, it was decided to examine these structures on the cadaveric model. 


\section{Conclusions}

The benefit of performing a cadaveric analysis of the common surgical approach used to gain access to the fracture plane is that it allows the description of the relative positions of all the key vessels, nerves and tendons. An awareness of the location of the smaller nerve branches is perhaps more useful than that of the major nerve trunks and vessels. Even in the swollen traumatised limb, the radial artery and the median nerve are visible to the naked eye. It is the smaller branches that are more liable to damage. Damage to these smaller structures, such as the palmar cutaneous branch of the median nerve, may not be immediately evident at the time of surgery.

There are no previous studies in the literature examining the three-dimensional relations of the extended FCR approach in the cadaveric model. This paper allows the surgeon to create an accurate picture of the surgical anatomy encountered on the radiovolar aspect of the forearm, and should hence reduce the risk of iatrogenic neurovascular injury.

\section{References}

1. Koval KJ, Harrast JJ, Anglen JO, Weinstein JN. Fractures of the distal part of the radius. The evolution of practice over time. Where's the evidence? J Bone Joint Surg Am 2008; 90: 1,855-1,861.

2. Leung $\mathrm{F}$, Zhu L, Ho $\mathrm{H}$ et al. Palmar plate fixation of $\mathrm{AO}$ type $\mathrm{C} 2$ fracture of distal radius using a locking compression plate - a biomechanical study in a cadaveric model. J Hand Surg Br 2003; 28: 263-266.

3. Levin SM, Nelson CO, Botts JD et al. Biomechanical evaluation of volar locking plates for distal radius fractures. Hand (NY) 2008; 3: 55-60.

4. Chung KC, Watt AJ, Kotsis SV et al. Treatment of unstable distal radial fractures with the volar locking plating system. J Bone Joint Surg Am 2006; 88: 2,687-2,694

5. Orbay JL, Fernandex DL. Volar fixed-angle plate fixation for unstable distal radius fractures in the elderly patient. J Hand Surg Am 2004; 29: 96-102.

6. Rozenthal TD, Blazar PE. Functional outcome and complications after volar plating for dorsally displaced, unstable fractures of the distal radius. $J$ Hand Surg Am 2006; 31: 359-365.

7. Oshige $\mathrm{T}$, Sakai A, Zenke $\mathrm{Y}$ et al. A comparative study of clinical and radiological outcomes of dorsally angulated, unstable distal radius fractures in elderly patients: intrafocal pinning versus volar locking plating. $J$ Hand Surg Am 2007; 32: 1,385-1,392.

8. McFadyen I, Field J, McCann P et al. Should unstable extra-articular distal radial fractures be treated with fixed-angle volar-locked plates or percutaneous Kirschner wires? A prospective randomised controlled trial. Injury 2011; 42: 162-166.

9. Voigt $\mathrm{C}$, Lill H. What advantages does volar plate fixation have over K-wire fixation for distal radius extension fractures in the elderly? Unfallchirurg 2006; 109: 845-846, 848-854.

10. Wright TW, Horodyski M, Smith DW. Functional outcome of unstable distal radius fractures: ORIF with a volar fixed-angle tine plate versus external fixation. J Hand Surg Am 2005; 30: 289-299.

11. Hoppenfeld S, deBoer P. Surgical Exposures in Orthopaedics. 3rd edn. Philadelphia, PA: Lippincott Williams \& Wilkins; 2003.

12. Orbay JL, Badia A, Indriago IR et al. The extended flexor carpi radialis approach: a new perspective for the distal radius fracture. Tech Hand Up Extrem Surg 2001; 5: 204-211.

13. Orbay J. Volar plate fixation of distal radius fractures. Hand Clin 2005; 21 : 347-354.

14. Downing ND, Karantana A. A revolution in the management of fractures of the distal radius? J Bone Joint Surg Br 2008; 90: 1,271-1,275.

15. Arora R, Lutz M, Hennerbichler $A$ et al. Complications following internal fixation of unstable distal radius fracture with a palmar locking-plate. J Orthop Trauma 2007; 21: 316-322.

16. Lattmann T, Dietrich M, Meier $C$ et al. Comparison of 2 surgical approaches for volar locking plate osteosynthesis of the distal radius. J Hand Surg Am 2008; 33: 1,135-1,143.
17. Berglund LM, Messer TM. Complications of volar plate fixation for managing distal radius fractures. J Am Acad Orthop Surg 2009; 17: 369-377.

18. Rampoldi M, Marsico S. Complications of volar plating of distal radius fractures. Acta Orthop Belg 2007; 73: 714-719.

19. Casaletto JA, Machin D, Leung R, Brown DJ. Flexor pollicis longus tendon ruptures after palmar plate fixation of fractures of the distal radius. J Hand Surg Eur Vol 2009; 34: 471-474.

20. Klug RA, Press CM, Gonzalez MH. Rupture of the flexor pollicis longus tendon after volar fixed-angle plating of a distal radius fracture: a case report. $J$ Hand Surg Am 2007; 32: 984-988.

21. Lifchez SD. Flexor pollicis longus tendon rupture after volar plating of a distal radius fracture. Plast Reconstr Surg 2010; 125: 21e-23e.

22. Valbuena SE, Cogswell LK, Baraziol R, Valenti P. Rupture of flexor tendon following volar plate of distal radius fracture. Report of five cases. Chir Main 2010: 29: 109-113.

23. Ishii $\mathrm{T}$, Ikeda M, Kobayashi $\mathrm{Y}$ et al. Flexor digitorum profundus tendon rupture associated with distal radius fracture malunion: a case report. Hand Surg 2009; 14: 35-38.

24. Koo SC, Ho ST. Delayed rupture of flexor pollicis longus tendon after volar plating of the distal radius. Hand Surg 2006; 11: 67-70.

25. Monda MK, Ellis A, Karmani S. Late rupture of flexor pollicis longus tendon 10 years after volar buttress plate fixation of a distal radius fracture: a case report. Acta Orthop Belg 2010; 76: 549-551.

26. Yamazaki H, Hattori Y, Doi K. Delayed rupture of flexor tendons caused by protrusion of a screw head of a volar plate for distal radius fracture: a case report. Hand Surg 2008; 13: 27-29.

27. Soong M, Earp BE, Bishop G et al. Volar locking plate implant prominence and flexor tendon rupture. J Bone Joint Surg Am 2011; 93: 328-335.

28. Dos Remedios C, Nebout J, Benlarbi $\mathrm{H}$ et al. Pronator quadratus preservation for distal radius fractures with locking palmar plate osteosynthesis. Surgical technique. Chir Main 2009; 28: 224-229.

29. Okazaki M, Tazaki K, Nakamura $T$ et al. Tendon entrapment in distal radius fractures. J Hand Surg Eur Vol 2009; 34: 479-482.

30. Thorpe P, Brown D. An unusual complication of distal radius plating. $J$ Hand Surg Eur Vol 2009; 34: 695-696.

31. Pichler W, Grechenig W, Clement $\mathrm{H}$ et al. Perforation of the third extensor compartment by the drill bit during palmar plating of the distal radius. J Hand Surg Eur Vol 2009; 34: 333-335.

32. Hattori Y, Doi K, Sakamoto S, Yukata K. Delayed rupture of extensor digitorum communis tendon following volar plating of distal radius fracture. Hand Surg 2008; 13: 183-185.

33. Perry DC, Machin DM, Casaletto JA, Brown DJ. Minimising the risk of extensor pollicis longus rupture following volar plate fixation of distal radius fractures: a cadaveric study. Ann R Coll Surg Engl 2011; 93: 57-60.

34. Buzzell JE, Weikert DR, Watson JT, Lee DH. Precontoured fixed-angle volar distal radius plates: a comparison of anatomic fit. J Hand Surg Am 2008; 33 : $1,144-1,152$.

35. Deepak VS, Giannoudis PV, Zelle BA et al. Radial artery tear complicating a distal radius fracture. Am J Orthop (Belle Mead NJ) 2005; 34: 299-300.

36. de Witte PB, Lozano-Calderon S, Harness $\mathrm{N}$ et al. Acute vascular injury associated with fracture of the distal radius: a report of 6 cases. J Orthop Trauma 2008; 22: 611-614.

37. Dao KD, Venn-Watson E, Shin AY. Radial artery pseudoaneurysm complication from use of AO/ASIF volar distal radius plate: a case report. J Hand Surg Am 2001; 26: 448-453.

38. Bederman SS, Anastakis DJ. Giant arteriovenous fistula of the upper extremity after distal radius fracture: a rare complication after a common problem. $J$ Trauma 2007; 63: E30-E33.

39. Kasper DA, Meller MM. Lymphedema of the hand and forearm following fracture of the distal radius. Orthopedics 2008; 31: 172.

40. Naff N, Dellon AL, Mackinnon SE. The anatomical course of the palmar cutaneous branch of the median nerve, including a description of its own unique tunnel. J Hand Surg Br 1993; 18: 316-317.

41. Matloub HS, Yan JG, Mink Van Der Molen AB et al. The detailed anatomy of the palmar cutaneous nerves and its clinical implications. J Hand Surg Br 1998; 23: 373-379.

42. DaSilva MF, Moore DC, Weiss AP et al. Anatomy of the palmar cutaneous branch of the median nerve: clinical significance. J Hand Surg Am 1996; 21: 639-643.

43. Das SK, Brown HG. In search of complications in carpal tunnel decompression. Hand 1976; 8: 243-249.

44. Lee HC, Wong YS, Chan BK, Low CO. Fixation of distal radius fractures using AO titanium volar distal radius plate. Hand Surg 2003; 8: 7-15. 
45. Glanvill R, Boon JM, Birkholtz $F$ et al. Superficial radial nerve injury during standard K-wire fixation of uncomplicated distal radial fractures. Orthopedics 2006; 29: 639-641.

46. Chia B, Catalano LW, Glickel SZ et al. Percutaneous pinning of distal radius fractures: an anatomic study demonstrating the proximity of K-wires to structures at risk. J Hand Surg Am 2009; 34: 1,014-1,020.

47. Habernek H, Weinstabl R, Schmid L. Anatomic studies of percutaneous bore wire osteosynthesis of the distal radius. Unfallchirurgie 1993; 19: 49-53.

48. Korcek L, Wongworawat M. Evaluation of the safe zone for percutaneous Kirschner-wire placement in the distal radius: cadaveric study. Clin Anat 2011; 24: 1,005-1,009.

49. Pirela-Cruz MA, Scher DL. Exposure of distal radius fractures using a direct radial approach with mobilization of the superficial branch of the radial nerve. Tech Hand Up Extrem Surg 2010; 14: 218-221.

50. McCann PA, Amirfeyz R, Wakeley C, Bhatia R. The volar anatomy of the dista radius - an MRI study of the FCR approach. Injury 2010; 41: 1,012-1,014.

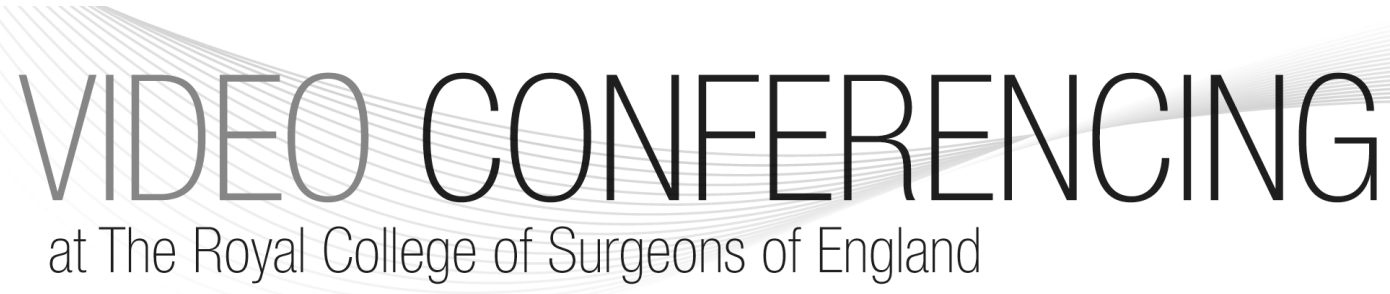

\section{If you're hosting or attending a meeting at The Royal College of Surgeons of England why not take advantage of the latest conference technology?}

With video conferencing, you can have twoway video and audio communication with any remote site in the world, saving you time, money and travel while you keep all the immediacy of a real-time, live conversation.

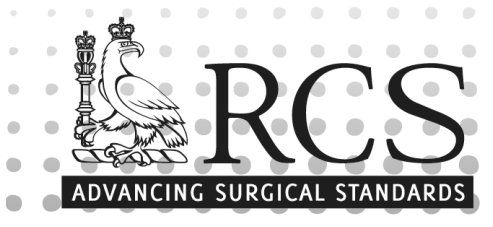

\author{
If you wish to make a booking or would like \\ further information on any of our services, \\ please contact us on media@rcseng.ac.uk \\ or visit uww.rcseng.ac.uk/conference-venue-hire/ \\ media-resources
}

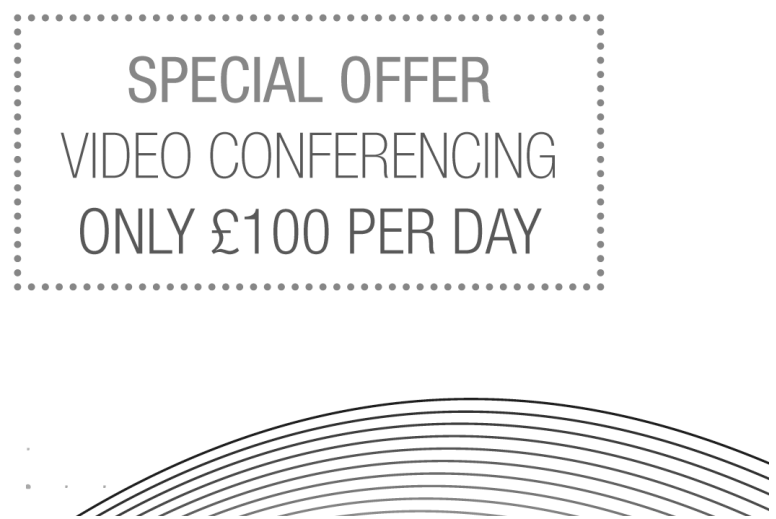

